\title{
Acerola by-product as a renewable source of bioactive compounds: arabic gum and maltodextrin nanocapsules
}

\author{
Alessandra Pinheiro de Góes CARNEIRO ${ }^{1}$, Antônia Livânia Linhares de AGUIAR², \\ Rudson Brendo Cordeiro da SILVA ${ }^{3}$, Ana Rosa RICHTER ${ }^{3}$, Paulo Henrique Machado de SOUSA ${ }^{1 *}$ (D), \\ Larissa Morais Ribeiro da SILVA ${ }^{2}$, Raimundo Wilane de FIGUEIREDO ${ }^{2}$
}

\begin{abstract}
Acerola industrial by-products present high levels of antioxidant compounds. Encapsulation technology has shown to be of great importance in the food industry. In this context, better nanoparticles are indicated in aiming to enrich food products with bioactive compounds. Five formulations were analyzed for yield, size distribution and zeta potential, infrared spectroscopy, encapsulation efficiency and doping. The yield data presented values from $38.01 \%$ to $44.34 \%$. The nanoparticles had sizes varying from $27.12 \mathrm{~nm}$ to $308.80 \mathrm{~nm}$ and negatively charged surfaces. The encapsulation efficiency was quantified based on the vitamin $\mathrm{C}$ content, total extractable polyphenols and antioxidant activity according to specific methodology taking into account the different compounds ranging from $25.44 \%$ to $69.37 \% ; 66.45 \%$ to $99.56 \%$ and $2.24 \%$ to $6.54 \%$, respectively. The above data indicate that nanoparticles made with acerola by-products and arabic gum/maltodextrin are promising as natural food additives, with high levels of bioactive compounds.
\end{abstract}

Keywords: acerola by-product; nanoparticle; bioactive; natural additive; gum arabic; maltodextrin.

Practical Application: This study investigates developing nanoparticles from industrial by-products of acerola using gum arabic and maltodextrin as wall material with the objective of enriching food products with bioactive compounds.

\section{Introduction}

Exotic tropical fruits are rich in bioactive compounds such as phenolic compounds, carotenoids, vitamins and food fibers. However, the processing industry of these fruits faces great difficulties related to the percentage of their by-products (such as unused peels, seeds and pulps) generated in the different stages of processing chains. In most cases, wasted by-products may contain similar or even higher bioactive compounds than the final product (Ayala-Zavala et al., 2011).

The use of waste at an industrial level is of interest to the food industry since it contributes to reducing environmental impacts in addition to reducing production costs. Industrial by-products are important to use in other products which can be industrialized and utilized as enrichers of these products. In this context, the use of renewable sources such as by-products and elaboration procedures based on the implementation of enriched and functional food products has received attention in the last decade due to the continuous growth of the world population, leading to a decrease in natural resources (Tolun et al., 2016).

Although acerola (Malpighia emarginata DC) is not a native plant to Brazil, it presents relevant production due to having adequate climate and soil conditions mainly in the Northeast Region (Antunes et al., 2013). It has high levels of two very well-known compound classes for their antioxidant properties: ascorbic acid (vitamin C), and phenolic compounds (Mercali et al., 2012).

By-products from the pulp and refiner showed high levels of vitamin C (175.76 and $525.18 \mathrm{mg} .100 \mathrm{~g}^{-1}$, respectively), total anthocyanins contents (19.43 and $20.54 \mathrm{mg} .100 \mathrm{~g}-1$, respectively), and polyphenols (545.98 mg gallic acid. $100 \mathrm{~g}^{-1}$ and $647.01 \mathrm{mg}$ gallic acid. $100 \mathrm{~g}^{-1}$, respectively), thus contributing to high antioxidant activity, being able to add value to products that have it as raw material (Carmo et al., 2018).

Encapsulation technology and the choice of new biopolymers have shown to be of great importance in the food industry, particularly in developing functional and healthy foods. Natural plant-based gums and their derivatives are widely utilized in food industries and these natural polymeric polysaccharides have many advantages because they are biodegradable, non-toxic, economical and easily available in the environment (Saha et al., 2017). Gum arabic and maltodextrin have been used to encapsulate phenolic extracts obtained from natural sources (Chranioti et al., 2015; Outuki et al., 2016; Mahdavee Khazaei et al., 2014). Ribeiro et al. (2019) optimized a mixed juice of acerola and seriguela by spray drying process using maltodextrin with $50 \%$ retention of ascorbic acid using $20 \%$ of maltodextrin 10 dextrose equivalent. 
Gum arabic is a versatile ingredient used in food systems due to its molecular flexibility, possessing functions such as emulsification, encapsulation, stabilization, and film forming, among others (Bai et al., 2017; Nale et al., 2018; Fernandes et al., 2014). Mixtures between different encapsulating agents are suggested in order to increase encapsulation effectiveness (Bae \& Lee, 2008; Boger et al., 2018; Mulcahy et al., 2018). Thus, the objective of this work was to encapsulate the bioactive substances of acerola by-product extract using gum arabic and maltodextrin matrix for its use as a nutritional aggregator in foods.

\section{Materials and methods}

\subsection{Materials}

The following were used for formulating the encapsulated material: gum arabic (GA) (VETEC); Maltodextrin (M) (SIGMA-ALDRICH); Tween 40 (TW) (SIGMA-ALDRICH); and extracts were performed using the by-products of freeze-dried acerola seed (from an acerola processing industry located in Tianguá/Ce, Brazil).

\subsection{Extraction procedure}

Distilled water was used to obtain the extract using an optimized method by Moreira (2014) and Carvalho (2014), considering that this extraction showed good results for Vitamin C, Total Extractable Polyphenols and Antioxidant Capacity. The extraction was carried out at the Federal University of Ceara (Ceará, Brazil), using $1 \mathrm{~g}$ of by-product to $4 \mathrm{~mL}$ of distilled water, homogenizing at $15000 \mathrm{rpm}$ in an Ultra Turrax (IKA T18 Basic) for $3 \mathrm{~min}$, then centrifuging (ROTINA 380/380R) at $10000 \mathrm{rpm}$ at $20^{\circ} \mathrm{C}$ for $10 \mathrm{~min}$ with the supernatant being filtered.

Regarding the chemical characterization of industrial acerola by-product extracts, three previously freeze-dried acerolas at $50^{\circ} \mathrm{C}$ were put in a $5 \mathrm{mtorr}\left(9.67 \times 10^{-5} \mathrm{psi}\right)$ vacuum for $48 \mathrm{~h}$ in a Labconco Freeze Dry-5 dryer (Labconco, MO). The freeze-dried material was stored in a desiccator protected from light until further use. The samples were submitted to an Vitamin C, Total Extractable Polyphenols and Antioxidant Activity analyses.

\subsection{Nanoparticle preparation}

Different formulations were prepared with variations in the amount (mass) of gum arabic, maltodextrin, and extract (Table 1). These analyzes were conducted in order to obtain the best concentration of wall material that promoted the most efficient preservation of bioactive compounds present in the acerola by-product extract.
The solutions of gum arabic and maltodextrin were initially prepared using distilled water (stirring at $50^{\circ} \mathrm{C}$ ). The solutions were mixed and Tween $40(0.01 \mathrm{~g} / 10 \mathrm{~mL})$ was added by dropping and stirring. The lyophilized acerola by-product extract was then added and measured to $100 \mathrm{~mL}$, and the solution was then homogenized in an Ultra Turrax (IKA T18 Basic) for 2 min (11.000 rpm). The obtained nanoparticle were prepared as previously reported by Paula et al. (2010), using a Mini Spray Dryer B-290 (BÜCHI, Switzerland) at an inlet temperature of $165 \pm 10^{\circ} \mathrm{C}$ and an outlet temperature of $70 \pm 10^{\circ} \mathrm{C}, 10 \mathrm{~mL}$ pump feed flow/ min, flow volume of $35 \mathrm{~m}^{3} / \mathrm{h}$, and aspirator flow of $90 \mathrm{~L} / \mathrm{h}$. The nanoencapsulated sample was stored in amber glass at room temperature $\left(25^{\circ} \mathrm{C}\right)$. The formulations were prepared in triplicate.

\subsection{Nanoparticle characterization}

Yield of atomization process $(\mathrm{Y})$ was calculated based on the solids content of the wall material and the amount of core material $(\mathrm{N})$ used for encapsulation through the soluble solids content according to Equation 1 (Jun-Xia et al., 2011).

$Y \%=[($ Final weight of nanoparticules $) /(M 1+M 2+N) \times 100$

Where: M1 = Gum arabic and M2 = Maltodextrin

Soluble solids (SS) determinations were performed using a digital refractometer (ATAGO PR-1010) with a of 0 to $45^{\circ}$ Brix scale by direct reading of the samples and after filtration on qualitative filter paper for by-products. The results were expressed in ${ }^{\circ} \mathrm{Brix}$, according to Instituto Adolfo Lutz (2008). In order to calculate the yield, the soluble solids present in the extract were taken into account to guarantee precision in the calculations.

The vitamin C (ascorbic acid) content was determined by the titration method using potassium iodate and based on the ascorbic acid oxidation by potassium iodate. The results were expressed as $\mathrm{mg} / 100 \mathrm{~g}$ of ascorbic acid (Instituto Adolfo Lutz, 2008).

Total extractable polyphenols were determined using the Folin-Ciocalteu reagent and gallic acid as standard, according to the methodology described by Larrauri et al. (1997).

Total antioxidant activity was determined according to the methodology described by Re et al. (1999) and Rufino et al. (2007). The readings for determining antioxidant activity were carried out in a spectrophotometer (Shimadzu model UV-1800) to $734 \mathrm{~nm}$. The results were expressed as equivalent antioxidant Trolox $^{\circledR}$ (TEAC) in $\mu \mathrm{M} \mathrm{g}^{-1}$.

The formulations were solubilized in distilled water in order to calculate the Entrapment efficiency (EE) at concentrations of $25 \mathrm{mg} / \mathrm{mL}$ for antioxidant activity; $1 \mathrm{mg} / \mathrm{mL}$ for polyphenols and

Table 1. Experimental planning used to elaborate nanoparticles containing acerola by-product extract.

\begin{tabular}{cccc}
\hline Nanoparticle & Gum arabic $(\mathrm{g})$ & Maltodextrin $(\mathrm{g})$ & Acerola by-product $(\mathrm{g})$ \\
\hline A & 0.25 & 0.25 & 1.75 \\
B & 0.50 & 0.25 & 1.75 \\
C & 0.75 & 0.25 & 1.75 \\
D & 0.25 & 0.50 & 1.75 \\
E & 0.25 & 0.25 & 2.0 \\
\hline
\end{tabular}


$5 \mathrm{mg} / \mathrm{mL}$ for vitamin $\mathrm{C}$ and then vortexed for $2 \mathrm{~min}$. The entrapment efficiency was calculated using Equation 2, where Ct represents the content of the component in the pure extract, and Cs the content of the component in the solubilized formulation (Alishahi et al., 2011).

$E E \%=[(C t-C s) / C t] \times 100$

The Doping (D) calculation was performed (Equation 3) by the difference of the bioactive compound levels present after the encapsulation process of each formulation $(\mathrm{Cb})$ by the final weight of the nanoparticle (Fw) (Paula et al., 2010).

$D \%=(C b \times 100) F w$

For Infrared Spectroscopy, the Fourier Transform Infrared (FT-IR) spectra were obtained on an 8300 Shimadzu spectrometer between 400 and $4000 \mathrm{~cm}^{-1}$. Samples were analyzed by absorbance on $\mathrm{KBr}$ pools.

Aqueous suspensions of nanoparticles $\left(5 \mathrm{mg} / \mathrm{mL}\right.$ at $\left.25^{\circ} \mathrm{C}\right)$ were submitted to particle size distribution analysis by Nano Zeta Sizer Malvern, Model ZS 3600 equipment, with continuous red light beam and wavelength at $633 \mathrm{~nm}$ and a spreading angle of $173^{\circ}$. The data were expressed as the mean of three readings (Paula et al., 2011).

\subsection{Statistical analysis}

Data were expressed as mean and standard deviation and determined in triplicate. Data were submitted to Analysis of Variance $(\mathrm{P}<0.05)$ and Tukey test using STATISTICA 7.0 software.

The multivariate principal components analysis technique was applied to reduce the studied variables (Vitamin C, PET and ATT) to only one in order to find the best formulation among the nanoparticles. Analysis of variance and the Tukey test were applied in order to find the formulation that generated higher averages.

\section{Results and discussion}

\subsection{Analysis of acerola by-product extract}

Acerola presents several substances with bioactive properties in its constitution. The acerola by-products presented high levels for vitamin $\mathrm{C}$, total extractable polyphenols and antioxidant activity (2726 mg/100 g, $4986 \mathrm{mg} \mathrm{AGE/100} \mathrm{g} \mathrm{and} \mathrm{216.05} \mathrm{uM}$ trolox/g, respectively). It was possible to confirm the great potential of acerola by-product use in other processes, such as encapsulation.

The ascorbic acid content in dry acerola residue found by Araújo et al. (2016) was $11.20 \pm 1.12 \mathrm{mg} / 100 \mathrm{~g}$, which is lower than that found for the acerola by-product described above. This content may be related to the types of cultivar, cultivation (organic) and by the type of drying (lyophilization).

The value of polyphenols extracted with water were quite high, which were higher than the values found by Moreira (2014) (691.42 mgGAE/100 g) and Carvalho (2014) (692.46 mgGAE/100 mg) using the same type of extraction in Acerola by-products. The antioxidant activity with extraction in water presented higher values than those found by Moreira (2014) and Carvalho (2014), which were $34.15 \mu \mathrm{M}$ trolox/g and $34.41 \mu \mathrm{M}$ trolox/g, respectively. Silva et al. (2014) emphasizes that phenolic compounds can be exploited at an industrial level as natural, safe and low cost preservatives. In addition to the antimicrobial effect, it contributes to maintaining and effectively improving human health.

With the data obtained from determining the bioactive compounds of the acerola by-product, it was possible to confirm the great potential of this sample for use in other processes such as encapsulation, and these parameters were used to verify the final quality of the produced material, providing the possibility of being used as a functional ingredient in many food products, especially foods which present low levels of these compounds.

\subsection{Nanoparticle characterization}

\section{Yield of atomization process}

Encapsulation yields of the formulations ranged from 38.01 to $44.34 \%$ (Figure 1). The mean value of soluble solids for the extracts used in the encapsulation was $6.07^{\circ} \mathrm{Brix}$. These data were used for the calculation as specified in Equation 1.

Increasing the amount of different coating material proportions resulted in a higher yield. This behavior reflects the increasing yield, even with the difficulty of adhesion of the samples in the spray dryer cyclone.

The low yield observed in this study may be due to the possibility of maltodextrin adhering to the drying chamber, and this fact was observed in studies by Tolun et al. (2016). Engel et al. (2016) reported that the process yield via spray dryer is highly affected by the amount of material retained inside the dryer.

Vitamin C, total extractable polyphenols and antioxidant activity of nanoparticles

The lowest value for vitamin $\mathrm{C}$ content was obtained for Formulation A. The highest content was found for formulation E (2349.43 $\pm 123.06 \mathrm{mg} / 100 \mathrm{~g})$ (Supplementary Material Table 1S).

It was verified that the increase in the gum arabic concentration is related to a decrease in the quantification of vitamin $C$ for the nanoparticles A, B and C. In analyzing the results obtained for

50

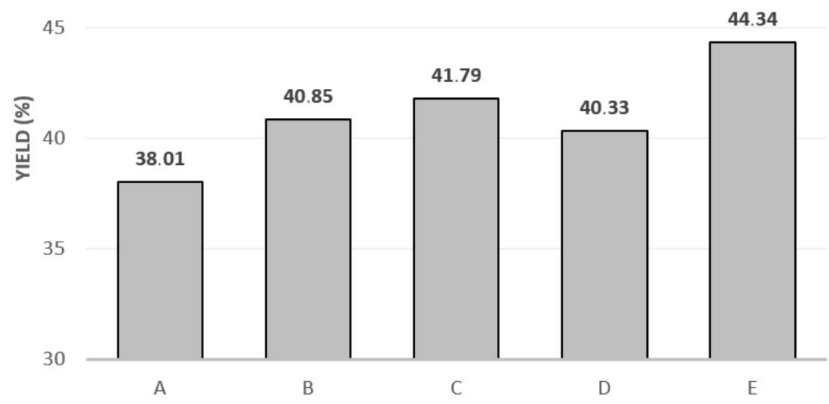

Figure 1. Yield after Spray Dryer process. 
Vitamin C for the nanoparticles B and C, it was observed that the increase in the amount of gum arabic resulted in a lower capacity for encapsulating vitamin C. The results obtained for the analyzed bioactive compound content demonstrated that the wall material is able to retain a larger amount of extract while maintaining the same initial conditions.

Several studies approaching different methods and wall materials for encapsulation of vitamin C (ascorbic acid) describe that this is a promising protection technology to overcome problems related to its application and its instability (Matos et al., 2015; Alvim et al., 2016). This can be confirmed by maintaining high levels of vitamin $\mathrm{C}$ after encapsulation, even though the drying process occurred at $160^{\circ} \mathrm{C}$, maintaining vitamin stability during processing.

The total extractable polyphenol contents found for the nanoparticles varied significantly between the formulations. The effect of the gum arabic increase on the total extractable polyphenols content shows that there was a decrease in the polyphenols quantification.

Nanoparticle E presented higher content of polyphenols and vitamin $\mathrm{C}$ when compared to the others, demonstrating that it is better adapted to retaining these bioactive compounds.

Total extractable polyphenols presented higher entrapment efficiency and content in the nanoparticles was high when compared to the results of lyophilized by-product extract (4392.84 mg GAE/100 g). Considering that the samples were formulated with this same extract in an amount of solids in the extract from $12.6 \%$ to $22.3 \%$, it is perceived that the preservation of polyphenol content is bound to both the amount of added extract and protection by encapsulation. Tolun et al. (2016) explain that since the coating material (maltodextrin and gum arabic) does not contain phenolic content, the total polyphenol content does not change with the coating mixture. These authors found values in the range of 5.20 to $16.50 \mathrm{mg} \mathrm{GAE} / 100 \mathrm{~g}$ of powder formulated with grape residue, with these values being similar to those in this study.
Araújo et al. (2016) found $446.40 \mathrm{mg}$ gallic acid.100 $\mathrm{g}^{-1}$ for dry acerola by-product. The values obtained by these authors are below those found for the lyophilized acerola by-product analyzed in this study, which presented $4392.84 \mathrm{mg} / 100 \mathrm{~g}$ of content. Vasco et al. (2008) define a high concentration of phenolic compounds above 1000, and this concentration is considered low for concentrations below 100. Thus, the samples evaluated in this study are classified as having a high concentration of phenolic compounds.

It was verified that nanoparticles $\mathrm{A}, \mathrm{B}, \mathrm{C}, \mathrm{D}$, and $\mathrm{E}$ presented no statistical difference $(\mathrm{p} \leq 0.05)$ for antioxidant activity. For antioxidant activity of grape residue microparticles coated with maltodextrin and gum arabic, Tolun et al. (2016) describe that the use of high temperatures for spray drying causes phenolic structure ruptures due to temperature and resynthesize in different ways, with possible alterations in the quantified values for the antioxidant activity. Although expressive, the low values such as those found in this study can be justified when compared to polyphenol content.

\section{Encapsulation Efficiency (EE\%)}

Encapsulation efficiency for vitamin C, polyphenols and antioxidant activity using nanoparticles $\mathrm{A}, \mathrm{B}, \mathrm{C}, \mathrm{D}$ and $\mathrm{E}$ (Figure 2) ranged from 38.01 to $44.34 \%$; from 66.45 to $99.56 \%$; and from 2.24 to $6.54 \%$, respectively. These values are within the expected range based on the studies of Herculano et al. (2015) and Fernandes et al. (2014).

This behavior is perceived from the results for vitamin C, polyphenols and antioxidant activity. In a study on the effects of gum arabic, modified starch, maltodextrin and inulin on the encapsulation of rosemary essential oil, Fernandes et al. (2014) describe that the encapsulation efficiency is one of the most important quality parameters due to quantification of the substance that is present in the encapsulated material.

Herculano et al. (2015) found encapsulation efficiencies from 24.89 to $26.80 \%$ for the content of eucalyptus essential oil encapsulated with cashew gum. These authors infer that increasing

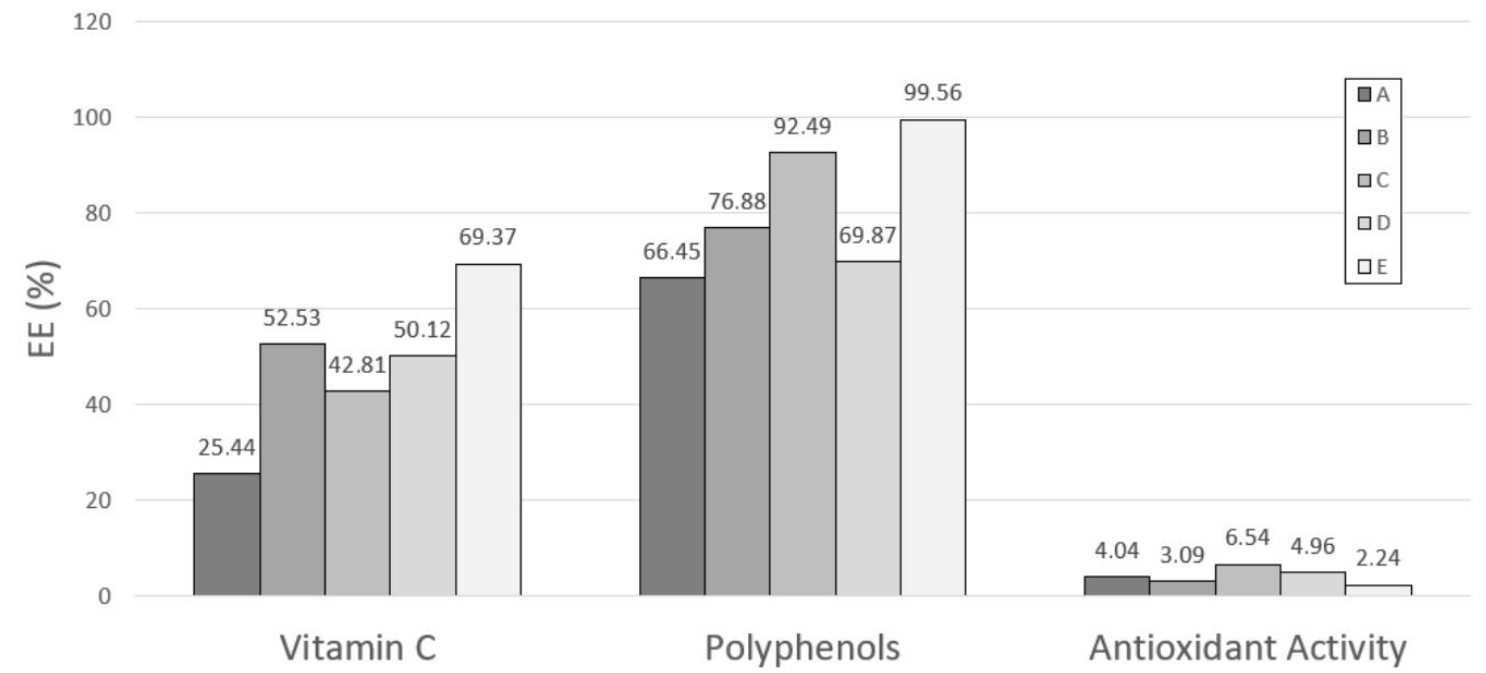

Figure 2. Encapsulation efficiency of acerola nanoparticles by-product extract for vitamin C, total extractable polyphenols and total antioxidant activity. 
the proportion of cashew gum increases the encapsulation efficiency, although at lower loading.

Different results were found for antioxidant activity with very low values being observed, which may be related to the preparation method of the nanoparticle to trigger the simultaneous release of other compounds that may have interfered in the results, or even related to lower solubility after encapsulation.

The results obtained by Tolun et al. (2016) indicate that the use of maltodextrin and gum arabic for encapsulating phenolic compounds extracted from grape residue provided better results than the use of maltodextrin alone as a coating material, exhibiting relatively high encapsulation efficiencies, and describing that even the maltodextrin alone provides good protection against oxidation.

\section{Doping}

Doping is related to the amount of bioactive compounds present in the nanoparticles after the nanoencapsulation process in terms of mass, with results expressed as a percentage.

There was variation from 0.95 to $2.35 \%$ for doping levels in the vitamin $\mathrm{C}$ analysis, with the lowest and highest values corresponding to nanoparticles $\mathrm{C}$ and $\mathrm{E}$, respectively (Figure 3 ).
The values for doping found by Paula et al. (2010) ranged from 1.20 to $10.70 \%$ for alginate and cashew gum microspheres as the encapsulating agent for croton zehntneri oil.

Doping levels for the analysis of total extractable polyphenols ranged from 0.22 to $0.36 \%$, with the lowest values for nanoparticles $\mathrm{C}$ and $\mathrm{D}$, and the highest value for nanoparticle $\mathrm{E}$.

It was not possible to perform quantification by this method for antioxidant activity, as the values found were extremely low. It should be taken into account that the doping calculation depends on the bioactive mass present. The results are strictly related to the encapsulation efficiency (EE), as these measures are directly proportional.

\section{FT-IR Spectroscopy}

The spectra of the wall material components used for the nanoparticle formulation are quite similar (Figure 4A), presenting bands around $3400 \mathrm{~cm}^{-1}$, which is characteristic of the $\mathrm{OH}$ stretching from water. The $\mathrm{CH}$ stretching under these conditions appears around $2924 \mathrm{~cm}^{-1}$ and the $\mathrm{OH}$ folding of the water around $1620 \mathrm{~cm}^{-1}$. It is also possible to verify the characteristic band of glycosidic binding of sugars around $1054 \mathrm{~cm}^{-1}$.

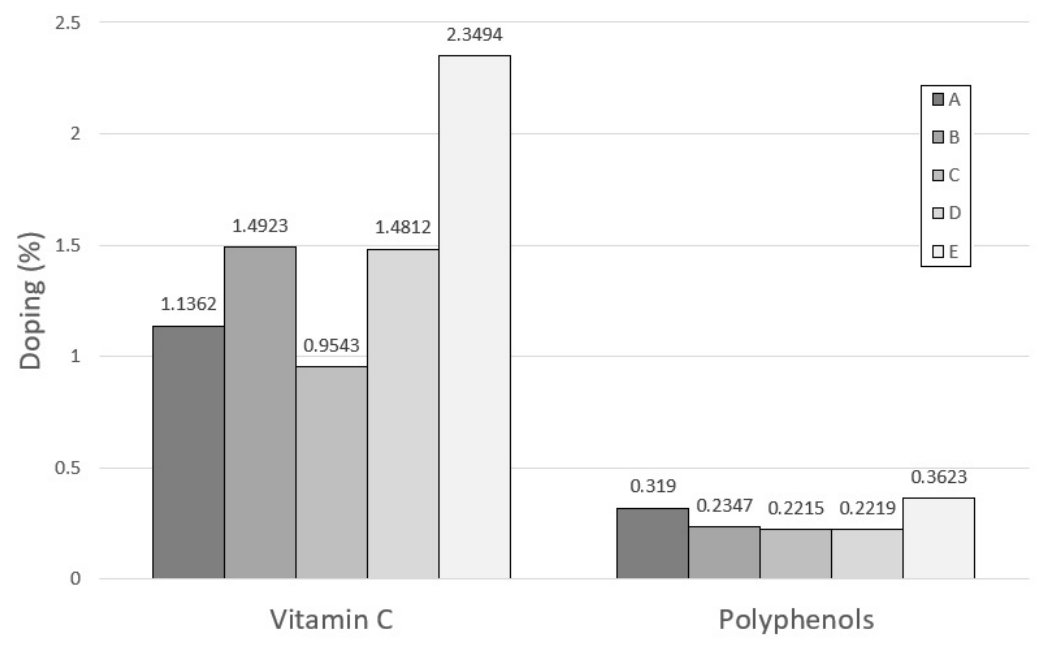

Figure 3. Doping of nanoparticles from the extract of bioactive compounds from acerola by-product obtained using spray-dryer.

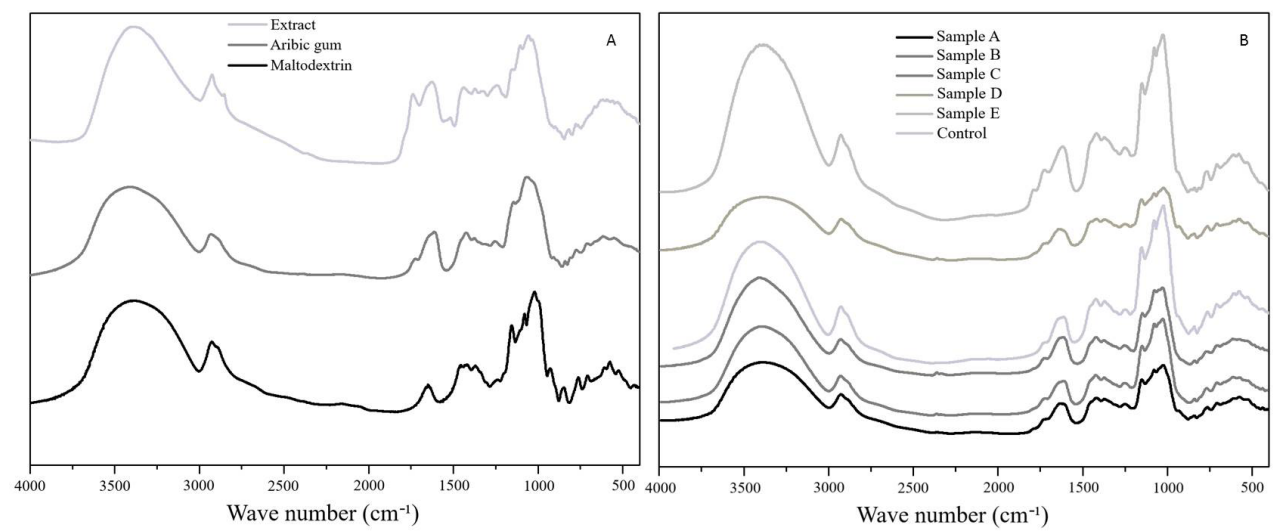

Figure 4. Infrared spectrum of Gum Arabic (GA), Maltodextrin (MA) and acerola by-product extract (A) and acerola by-product extract nanoparticles (B). 
These bands identify chemical bonds that absorb energy at different wavelengths, determining the possible presence of some compounds. Similar spectra were found for different materials (Herculano et al., 2015; Gómez-Mascaraque et al., 2015).

The spectra were within the expected range for the evaluated nanoparticles (Figure 4B), with characteristic peaks of the phenolic compounds and vitamin C (bands between 1200 and $900 \mathrm{~cm}^{-1}$ ) wall materials (gum arabic and maltodextrin) in all treatments. These characteristics indicated that the bioactive compounds present in the nanoparticles were preserved during the encapsulation process via spray dryer.

All acerola by-product extract nanoparticles have very similar absorption profiles because they are sugar spectrum, presenting all the characteristic bands of the wall materials and not allowing to infer differences, even with the variation in acerola extract proportions for the formulations. This is due to nanoparticle $\mathrm{E}$ presenting double the acerola by-product extract and the control sample only presenting the wall material.

The control sample also shows the same absorption profile with the characteristic bands, but with little intensity. Monteiro et al. (2015) also found similarity between the FTIR spectra of their polyelectrolyte complexes in the formation of microspheres and the spectra of their wall materials.

Saffarzadeh-Matin \& Shahbazi (2018) prepared an apple pomace polyphenolic extract loaded into biodegradable and commercially available natural polymer such as maltodextrin and identified the functional groups of the active components and also any interaction modes between the polymeric wall and the polyphenolic core by FTIR.

\section{Particle size distribution; Polydispersion Index and Zeta Potential}

The particle size ranged from $27.12 \mathrm{~nm}$ to $308.80 \mathrm{~nm}$, with bimodal distribution for all formulations (Table 2). Similar size values $(27.70 \mathrm{~nm}$ at $308.08 \mathrm{~nm}$ ) and negatively charged surfaces were found by Herculano et al. (2015) in studying the physicochemical properties of encapsulated eucalyptus essential oil in a cashew gum matrix.

The polydispersion index represents the particle size distribution, and values ranging from 0.399 to 0.898 were observed for the analyzed nanoparticles, indicating heterogeneity of the particle size distribution resulting from the formation of polydispersed systems. This behavior was expected, since the particle size presented a bimodal shape.

The zeta potential was measured in order to verify the surface charges of the particles, which can predict the material stability being influenced by the changes in the interface with the dispersing medium, which in this case was water. When analyzing the results for zeta potential, it is observed that the highest value occurred for nanoparticle $\mathrm{B}$ $(-28.3 \mathrm{mV})$ and the lowest value for $\mathrm{F}(-15.3 \mathrm{mV})$, thus signaling good electrostatic stability when in suspension. This indicates the presence of negative surface charges due to carboxyl groups present in the gum arabic because it is dissolved in polar liquid (water).

\section{Determining the best formulation}

Several studies have recently been carried out aiming to indicate compounds encapsulated for use in food. Costa et al. (2018) microencapsulated Cupuassu (Theobroma grandiflorum Schum.) extract and also suggest its use to formulate new foods or pharmaceuticals.

The choice of the best nanoparticle in this study was through a multivariate analysis using the variables: vitamin C, polyphenols and antioxidant activity. An analysis of main components was performed with these three variables, only selecting the first component which explains $63.63 \%$ of the original data variance.

The scores of the main component chosen were generated from the function:

$$
\mathrm{E}_{\mathrm{i}}=0.699^{*} \mathrm{Z}_{\mathrm{i} \text { Vitamin C }}+0.678^{\star} \mathrm{Z}_{\mathrm{i} \text { Polyphenols }}+0.227^{\star} \mathrm{Z}_{\text {iantioxidant activity }}
$$

Where $\mathrm{Z}$ represents the original values of the variables subtracted from their mean and divided by their standard deviation.

It was verified that nanoparticle $\mathrm{E}$ presented the highest result for the vitamin $\mathrm{C}$, polyphenol and antioxidant activity variables by applying the multivariate analysis, indicating that it is the best particle to be used in food application.

Table 2. Particle size distribution values, polydispersion Index (PDI) and zeta potential (mV) of the nanoparticles of acerola by-product extract obtained by spray dryer.

\begin{tabular}{cccc}
\hline Formulation & Particle size distribution $(\mathrm{nm})$ & Polydispersion Index $(\mathrm{PDI})$ & Zeta Potential $(\mathrm{mV})$ \\
\hline A & $287.5 \pm 144.3(65.3 \%)$ & 0.898 & $-23.2 \pm 7.98$ \\
& $36.89 \pm 16.2(31.1 \%)$ & & 0.515 \\
B & $215.8 \pm 38.52(66.2 \%)$ & & $-28.3 \pm 5.96$ \\
& $27.12 \pm 5.02(33.8 \%)$ & 0.745 & $-15.8 \pm 9.25$ \\
C & $46.99 \pm 21.94(54.9 \%)$ & 0.399 & $-25.4 \pm 4.33$ \\
& $291.5 \pm 106.3(38.0 \%)$ & & $-23.8 \pm 7.05$ \\
D & $308.8 \pm 75.11(51.4 \%)$ & 0.797 & \\
\end{tabular}




\section{Conclusion}

The use of acerola by-products is a promising alternative to obtain encapsulated products rich in bioactive compounds with antioxidant activity, confirming its potential to be used as an additive in the food industry.

The nanoparticles produced in this study have potential as a food additive to be incorporated as a functional ingredient in a range of foods in order to improve the stability of bioactive compounds during storage, having a huge impact in industry and the health sector.

The gum arabic and maltodextrin matrix were shown to be efficient in retaining compounds such as vitamin C, total extractable polyphenols and antioxidant activity in all formulations, as well as showing particle size and distribution with a certain stability, which shows little tendency to aggregate when in solution.

All the nanoparticles presented as being a good source of vitamin C, polyphenols and antioxidant activity. It is recommended to use nanoparticle $\mathrm{E}$ as it presented more constant results, but the results found for the other nanoparticles should also be taken into account.

\section{Acknowledgements}

The authors thank CAPES (Coordination for the Improvement of Higher Level Personnel), CNPq (National Council for Scientific and Technological Development, Process 150074/2017-4), the Laboratory of Fruits and Vegetables (DEAL) and the Laboratory of Chemistry of Biopolymers (LABIOPOL) for their support.

\section{References}

Alishahi, A., Mirvaghefi, A., Tehrani, M. R., Farahmand, H., Shojaosadati, S. A., Dorkoosh, F. A., \& Elsabee, M. Z. (2011). Shelf life and delivery enhancement of vitamin $\mathrm{C}$ using chitosan nanoparticles. Food Chemistry, 126(3), 935-940. http://dx.doi.org/10.1016/j. foodchem.2010.11.086.

Alvim, I. D., Stein, M. A., Koury, I. P., Dantas, F. B. H., \& Cruz, C. L. C. V. (2016). Comparison between the spray drying and spray chilling microparticles contain ascorbic acid in a baked product application. Food Science and Technology, 65(1), 689-694. http:// dx.doi.org/10.1016/j.lwt.2015.08.049.

Antunes, A. E. C., Liserre, A. M., Coelho, A. L. A., Menezes, C. R., Moreno, I., Yotsuyanagi, K., \& Azambuja, N. C. (2013). Acerola nectar with added microencapsulated probiotic. LebensmittelWissenschaft + Technologie, 54(1), 125-131. http://dx.doi.org/10.1016/j. lwt.2013.04.018.

Araújo, A. P. O., Santos, E. C. C., Damasceno, F. S., Deboni, T. M., Cuevas, M. S., \& Mota, R. V. (2016). Use of experimental design in the study of acerola juice pasteurization. Scientia Plena, 12(6), 1-8.

Ayala-Zavala, J. F., Vega-Vega, V., Rosas-Domínguez, C., Palafox-Carlos, H., Villa-Rodriguez, J. A., Siddiqui, M. W., Dávila-Aviña, J. E., \& González-Aguilar, G. A. (2011). Agro-industrial potential of exotic fruit byproducts as a source of food additives. Food Research International, 44(7), 1866-1874. http://dx.doi.org/10.1016/j.foodres.2011.02.021.

Bae, E. K., \& Lee, S. J. (2008). Micorencapsulation of avocado oil by spray drying using whey protein and maltodextrin. Journal of Microencapsulation, 25(8), 549-560. http://dx.doi.org/10.1080/02652040802075682. PMid:18465295.
Bai, L., Huan, S., Li, Z., \& McClements, D. J. (2017). Comparison of emulsifying properties of food-grade polysaccharides in oil-inwater emulsions: Gum arabic, beet pectin, and corn fiber gum. Food Hydrocolloids, 66, 144-153. http://dx.doi.org/10.1016/j. foodhyd.2016.12.019.

Boger, B. R., Georgetti, S. R., \& Kurozawa, L. E. (2018). Microencapsulation of grape seed oil by spray drying. Food Science and Technology (Campinas), 38(2), 263-270. http://dx.doi.org/10.1590/fst.04417.

Carmo, J. S., Nazareno, L. S. Q., \& Rufino, M. (2018). Characterization of the acerola industrial residues and prospection of their potential application as antioxidant dietary fiber source. Food Science and Technology, 38(Suppl. 1), 236-241. http://dx.doi.org/10.1590/fst.18117.

Carvalho, W. M. (2014). Encapsulation of by-products of acerola (Malpighia emarginata D.C.) in gum matrix for coating of minimally processed melon (Master's thesis). Universidade Federal do Ceará, Ceará. p. 113.

Chranioti, C., Nikoloudaki, A., \& Tzia, C. (2015). Saffron and beetroot extracts encapsulated in maltodextrin, gum Arabic, modified starch and chitosan: Incorporation in a chewing gum system. Carbohydrate Polymers, 127, 252-263. http://dx.doi.org/10.1016/j. carbpol.2015.03.049. PMid:25965482.

Costa, R. S., Teixeira, C. B., Gabbay Alves, T. V., Ribeiro-Costa, R. M., Cazassa, A. A., Aliakbarian, B., Converti, A., Junior, J. O. C., \& Perego, P. (2018). Optimization of spray drying conditions to microencapsulate cupuassu (Theobroma grandiflorum) seed byproduct extract. Natural Product Research, 14, 1-9. http://dx.doi.or g/10.1080/14786419.2018.1548448. PMid:29656659.

Engel, B., Baccar, N. M., Marquardt, L., Oliveira, M. S. R., \& Rohlfes, A. L. B. (2016). Atomization and dehydration technologies: Alternatives for the production of flours from vegetables. Revista Jovem Pesquisador, 6(1), 31-34.

Fernandes, R. V., Borges, S. V., \& Botrel, D. A. (2014). Gum arabic/starch/ Maltodextrin/inulin as wall materials on the microencapsulation of rosemary essential oil. Carbohydrate Polymers, 1, 524-532. http:// dx.doi.org/10.1016/j.carbpol.2013.09.083. PMid:24299808.

Gómez-Mascaraque, L. G., Lagarón, J. M., \& López-Rubio, A. (2015). Electrosprayed gelatin submicroparticles as edible carriers for the encapsulation of polyphenols of interest in functional foods. Food Hydrocolloids, 49, 42-52. http://dx.doi.org/10.1016/j.foodhyd.2015.03.006.

Herculano, E. D., Paula, H. C. B., Figueiredo, E. A. T., Dias, F. G. B., \& Pereira, V. A. (2015). Physicochemical and antimicrobial properties of nanoencapsulated Eucalyptus staigeriana essential oil. Lebensmittel-Wissenschaft + Technologie, 61(2), 484-491. http:// dx.doi.org/10.1016/j.lwt.2014.12.001.

Instituto Adolfo Lutz - IAL. (2008). Physicochemical methods for food analysis. São Paulo: Instituto Adolfo Lutz.

Jun-Xia, X., Hai-Yan, Y., \& Jian, Y. (2011). Microencapsulation of sweet orange oil by complex coacervation with soybean protein isolate/ Gum Arabic. Food Chemistry, 125(4), 1267-1272. http://dx.doi. org/10.1016/j.foodchem.2010.10.063.

Mahdavee Khazaei, K., Jafari, S. M., Ghorbani, M., \& Hemmati Kakhki, A. (2014). Application of maltodextrin and gum Arabic in microencapsulation of saffron petal's anthocyanins and evaluating their storage stability and color. Carbohydrate Polymers, 105(25), 5762. http://dx.doi.org/10.1016/j.carbpol.2014.01.042. PMid:24708952.

Larrauri, J. A., Rupérez, P., \& Saura-Calixto, F. (1997). Effect of drying temperature on the stabilitity of polyphenols and antioxidant activity of red grape pomace peels. Journal of Agricultural and Food Chemistry, 45(4), 1390-1393. http://dx.doi.org/10.1021/jf960282f.

Matos, F. E. Jr, Di Sabatino, M., Passerini, N., Favaro-Trindade, C. S., \& Albertini, B. (2015). Development and characterization of solid 
lipid microparticles loaded with ascorbic acid and produced by spray congealing. Food Research International, 67, 52-59. http:// dx.doi.org/10.1016/j.foodres.2014.11.002.

Mercali, G. D., Jaeschke, D. P., Tessaro, I. C., \& Marczak, L. D. F. (2012). Study of vitamin C degradation in acerola pulp during ohmic and conventional heat treatment. Food Science and Techolony, 47(1), 91-95. http://dx.doi.org/10.1016/j.lwt.2011.12.030.

Monteiro, A. A. S., Richter, A. R., Maciel, J. S., Feitosa, J. P. A., Paula, H. C. B., \& Paula, R. C. M. (2015). Effect of chemical modification on the solubility and swelling of microspheres based on carboxymethyl cashew gum and chitosan. Polímeros, 25, 31-39. http://dx.doi. org/10.1590/0104-1428.1779.

Moreira, S. P. (2014). Evaluation of the quality and safety of minimally processed melon coated in chitosan matrix added with microencapsulated bioactive compounds extracted from acerola by - products (Master's thesis). Universidade Federal do Ceará, Ceará.

Mulcahy, E., Park, C. W., Drake, M., Mulvihill, D. M., \& O’Mahony, J. A. (2018). Enhancement of the functional properties of whey protein by conjugation with maltodextrin under dry heating conditions. International Journal of Dairy Technology, 71(1), 216-225. http:// dx.doi.org/10.1111/1471-0307.12411.

Nale, Z., Tontul, I., Arslan, A. A., Nadeem, H. S., \& Kucukcetin, A. (2018). Microbial viability, physicochemical and sensory properties of kefir microcapsules prepared using maltodextrin/Arabic gum mixes. International Journal of Dairy Technology, 71(S1), 61-72. http://dx.doi.org/10.1111/1471-0307.12402.

Outuki, P. M., de Francisco, L. M. B., Hoscheid, J., Bonifácio, K. L., Barbosa, D. S., \& Cardoso, M. L. C. (2016). Development of arabic and xanthan gum microparticles loaded withan extract of Eschweilera nana Miers leaves with antioxidant capacity. Colloids and Surfaces. A, Physicochemical and Engineering Aspects, 499, 103-112. http:// dx.doi.org/10.1016/j.colsurfa.2016.04.006.

Paula, H. C. B., Paula, R. C. M., Morais, S. M., \& Forte, M. C. (2010). Esferas (beads) de alginato como agente encapsulante de óleo de croton zehntneri Pax et Hoffm. Polímers, 20(2), 112-120. http:// dx.doi.org/10.1590/S0104-14282010005000019.

Paula, H. C. B., Sombra, F. M., Cavalcante, R. D. F., Abreu, F. O. M. S., \& Paula, R. C. M. (2011). Preparation and characterization of chitosan/cashew gum beads loaded with Lippia sidoides essential oil. Materials Science and Engineering, 31(2), 173-178. http://dx.doi. org/10.1016/j.msec.2010.08.013.

Re, R., Pellegrini, N., Proteggente, A., Pannala, A., Yang, M., \& RiceEvans, C. (1999). Antioxidant activity applying and improved ABTS radical cátion decolorization assay. Free Radical Biology \& Medicine, 26(9-10), 1231-1237. http://dx.doi.org/10.1016/S08915849(98)00315-3. PMid:10381194.

Ribeiro, C. M. C. M., Magliano, L. C. S. A., Costa, M. M. A., Bezerra, T. K. A., \& Silva, F. L. H. (2019). Optimization of the spray drying process conditions for acerola and seriguela juice mix. Food Science and Technology, 39(Suppl. 1), 48-55. http://dx.doi.org/10.1590/fst.36217.

Rufino, M. S. M., Alves, R. E., \& Brito, E. S. (2007). Scientific Methodology: Determination of the total antioxidant activity in fruits by the capture of free radical $A B T S+$ (Comunicado Técnico, 128). Fortaleza: Embrapa Agroindústria Tropical.

Saffarzadeh-Matin, S., \& Shahbazi, M. (2018). Maltodextrine nanoparticles loaded with polyphenolic extract from apple industrial waste: preparation, optimization and characterization. Journal of Particle Science \& Technology, 15(4), 197-209.

Saha, A., Tyagi, S., Gupta, R. K., \& Tyagi, Y. K. (2017). Natural gums of plant origin as edible coatings for food industry applications. Critical Reviews in Biotechnology, 37(8), 1-15. http://dx.doi.org/10 .1080/07388551.2017.1286449. PMid:28423942.

Silva, L. M. R., Figueiredo, E. A. T., Ricardo, N. M. P., Vieira, I. C. P., Figueiredo, R. W., Brasil, I. M., \& Gomes, C. L. (2014). Quantification of bioactive compounds in pulps and by-products of tropical fruits from Brazil. Food Chemistry, 143, 398-404. http://dx.doi.org/10.1016/j. foodchem.2013.08.001. PMid:24054258.

Tolun, A., Altintas, Z., \& Artik, N. (2016). Microencapsulation of grape polyphenols using maltodextrin andgum arabic as two alternative coating materials: Development and characterization. Journal of Biotechnology, 239(33), 23-33. http://dx.doi.org/10.1016/j. jbiotec.2016.10.001. PMid:27720817.

Vasco, C., Ruales, J., \& Kamal-Eldin, A. (2008). Total phenolic compounds and antioxidant capacities of major fruits from Ecuador. Food Chemistry, 111(4), 816-823. http://dx.doi.org/10.1016/j.foodchem.2008.04.054. 


\section{Supplementary Material}

Supplementary material accompanies this paper.

Table 1S. Quantification of Vitamin C, total extractable polyphenols and antioxidant activity of formulations encapsulated by spray dryer.
This material is available as part of the online article from http:// www.scielo.br/cta 